\title{
The role of clinical dashboards in improving patient care: experience with the 'Maternity Dashboard'
}

\author{
E Chandraharan, S Arulkumaran \\ Ceylon Medical Journal 2016; 61: 83-85 \\ DOI: http://doi.org/10.4038/cmj.v61i2.8291
}

\begin{abstract}
What is the Maternity Dashboard?
The 'Maternity Dashboard' is a clinical performance and governance score card which enables monitoring of various pre-selected parameters at a regular (monthly) interval. Local, regional or national goals or benchmarks are used to compare the current performance against expected standards. This would help not only to identify and promote areas of good clinical practice to safeguard patient care in maternity service, but also may help detect and rectify areas that need improvement. Rarely, the Maternity Dashboard may help identify unsafe clinical practice. A good practice series on the Maternity Dashboard has been produced by the Royal College of Obstetricians and Gynaecologists (RCOG) and this was subsequently recommended by the Chief Medical Officer in the UK $[1,2]$.
\end{abstract}

\section{How to choose the parameters to be monitored}

The aim of the Maternity Dashboard is to ensure that the principles of clinical governance are safeguarded in daily clinical practice. Clinical governance refers to the framework through which healthcare organisations are expected to safeguard good clinical practice while continuously improving care so that clinical excellence would flourish [3]. In addition to 'preselecting' a group of 'general' parameters that would facilitate comparison of performance with other (similar) maternity units (such as normal birth rate, caesarean section rate and instrumental vaginal birth, and induction of labour rates, as well as the rate of massive obstetric haemorrhage), locally determined parameters to gauge the performance of the maternity unit are equally important. These local parameters need to be selected by the multi-disciplinary team (such as the Obstetric Risk Management team) with input from neonatologists, anaesthetists and user groups. These local parameters should reflect areas of clinical care that require improvement, based on clinical observation. For example, if there is an observed increase in the rate of emergency caesarean sections or third degree perineal tears the clinical practice needs to be monitored to identify contributing factors such as errors in fetal monitoring or failed instrumental deliveries. This may help identify a 'training issue' with regard to instrumental vaginal births that could be easily rectified by conducting 'one to one' hands on training. Similarly, monitoring patient 'complaints and compliments' may identify areas in maternity service, which need to be improved.

Once compliance with the 'locally set' standard has been achieved and monitored for some time, it may be removed from the Maternity Dashboard and new parameters may be considered for monitoring. It is important to use the Maternity Dashboard as a 'dynamic' clinical governance tool to monitor evolving risks and performance issues in a maternity unit. To ensure a systematic approach, individual parameters may be grouped under broad categories (e.g. 'clinical activity', 'workforce', 'risk management' and 'responsive care') on the Maternity Dashboard.

\section{How to set the 'standards' or 'goals'}

It is important to set a 'gold standard' or 'goal' for each parameter that is monitored on the Maternity Dashboard as it will help assess the quality of maternity care provided and to identify shortcomings, if any. National, local or evidence-based guidelines may be used to set the thresholds for these standards. One may modify the National Standards to reflect local case mix or population characteristics. For example, a tertiary institution that delivers care to a high-risk population or receives in-utero transfers for complex maternal and fetal conditions may have a higher rate of neonatal morbidity and mortality when compared to a ordinary institution.

Individual maternity units should set upper and lower thresholds for each of the standards to assess performance against the set standards. A suggested approach is to use the 'traffic light' system with green (to indicate when the

Department of Obstetrics and Gynaecology, St George's University Hospitals NHS Foundation Trust, London, UK.

Correspondence: EC, e-mail: <edwin.c@sky.com>. Received 8 March 2016.

This is an open-access article distributed under the terms of the Creative Commons Attribution License, which permits unrestricted use, distribution, and reproduction in any medium, provided the original author and source are credited. 
goals are met), amber (to indicate that the goals are not met i.e. above the lower threshold, but still within the upper threshold) and red (when the upper threshold is breached). Such a colour-coded system may give an immediate visual feedback for providers, commissioners and users of the maternity service to understand the performance of the maternity unit easily.

\section{Collection of data}

The data should be reliable and could be obtained from software systems (Euroking, Datix) or may have to be collected manually. It is vital to cross-check the data with the operation theatre book or the labour ward admissions for accuracy and relevance. Data on patient complaints and compliments could be obtained from the Complaints Department or patient advisory and liaison service (PALS). A strong clinical leadership and ownership is essential to ensure that the data disseminated through the Maternity Dashboard are reliable, relevant and are of a very high quality.

\section{Suggested actions}

If a parameter scores amber, it requires a closer scrutiny and necessary action should be taken to bring this parameter back to green. A closer observation of the parameter to identify any trends in subsequent months may be all that is required. However, frequent or repeated ambers in any single parameter should necessitate corrective action to avoid deterioration to red in subsequent months. A parameter that scores red requires urgent action, as it has breached the upper limit of the locally set standard. It may pose an impending threat to patient safety or adversely affect the quality of maternity care provided.

\section{Our experience}

The Maternity Dashboard was introduced at St. George's Hospital, London, UK in January 2007, as a tool to monitor various aspects of clinical governance and to help improve patient care and outcomes [4]. Lessons learnt and advantages we had are given below.

\section{a. Dissemination of information}

In our experience, The Maternity Dashboard has been a useful tool to disseminate information about the overall performance of the maternity unit to all staff, management, commissioners and users of the service. The Maternity Dashboard is sent via email to the leads of clinical areas for dissemination to all staff, trust management including our chief executive, local commissioners as well as to our 'user representatives', every month. It is also widely discussed in our multidisciplinary meetings as well as at our Maternity Services Liaison Committee (MSLC) meeting on a monthly basis.

\section{b. Safeguarding good clinical care}

The Maternity Dashboard helped our team to appreciate areas of good practice such as our low emergency caesarean section rate, failed instrumental vaginal delivery rate and the hypoxic ischaemic encephalopathy (HIE) rate.

\section{c. Continuously improving clinical care}

The Maternity Dashboard was instrumental in helping us to identify and scrutinise clinical areas that scored amber or red. Following an observed increase in the rate of third degree perineal tears in 2007, we conducted an audit, which revealed that the majority of these were associated with instrumental vaginal births involving a single clinician. Following measures that were put in place to safeguard patient safety, while supporting and providing 'one to one' training to the clinician concerned, this parameter returned to green in subsequent months after this intervention. 'One to one' hands-on training on operative vaginal births were offered for all obstetric trainees to avoid recurrence.

\section{d. Rectifying errors in systems and processes}

The Maternity Dashboard has been a good 'evidencetool' in our arguments to improve our local facilities, staffing levels and our resources. We were able to show the trust management and local commissioners about the increasing number of bookings, births, shortfalls in midwifery and obstetric staffing levels, as well as patient feedback by regularly monitoring and reporting these parameters through our Maternity Dashboard [5].

e. Ownership and engagement of the multi-disciplinary team

The Maternity Dashboard has offered us an excellent opportunity to interact as a multi-disciplinary team and to identify areas of excellent clinical practice as well as areas that needed improvement. Monthly dissemination of data has helped the members of the multi-disciplinary team to understand and appreciate areas of good practice and the challenges faced by various sectors within our maternity service.

\section{Potential challenges}

Maternity Dashboard requires individual as well as collective ownership and leadership to continuously improve patient care and outcomes. Significant time commitment and good quality data are important. Setting the goals requires a multi-disciplinary input. Although it is desirable to accommodate the requests of every member of the team, it is also vital to ensure that the Maternity Dashboard is not overloaded with too many parameters. 
Otherwise, it may become just another 'paper exercise' leading to the loss of engagement with the stakeholders. Senior management team should allocate both time and resources to ensure the successful implementation and continuation of the Maternity Dashboard.

\section{Conclusions}

Clinical dashboards or 'score cards' help monitor performance against set standards or goals and thereby, may help safeguard good clinical practice and help continuously improve outcomes. Our experience with the Maternity Dashboard during the last eight years at St. George's University Hospitals NHS Foundation Trust, London demonstrates that the Maternity Dashboard is an invaluable tool to rectify staffing and resource issues, monitor performance and to continuously improve patient care and outcomes [6].

\section{Conflicts of interests}

There are no conflicts of interest.

\section{References}

1. Royal College of Obstetricians and Gynaecologists. Maternity Dashboard: Clinical Performance and
Governance Score Card. Good Practice Series No. 7. RCOG Press. Jan 2008.

http://www.rcog.org.uk/womens-health/clinical-guidance/ maternity-dashboard-clinical-performance-and-governancescore-card

2. Department of Health. On the State of Public Health: Annual Report of the Chief Medical Officer 2006. Chapter 6: Intrapartum-related deaths: 500 missed opportunities. London: The Stationery Office; 2007 www.dh.gov.uk/en/ Publicationsandstatistics/Publications/ Annual Reports/ DH_076817.

3. Chandraharan E, Arulkumaran S. Clinical Governance. Obstetrics, Gyn Reproductive Med 2007; 17: 222-4.

4. Chandraharan E, Sutton J, Beattie J, Arulkumaran S. The role of the 'Maternity Dashboard' in improving patient care: 2 year experience at a tertiary centre. Int J Gynecol Obstet 2009; 107 (suppl2): S139.

5. Royal College of Obstetricians and Gynaecologists. Safer Childbirth: Minimum Standards for Organisation and Delivery of Care in Labour. Midwifery Staffing Levels. London: RCOG Press; 2007. www.rcog.org.uk/resources/ public/pdf/safer_childbirth_report_web.pdf

6. Chandraharan E. Clinical Dashboards: do they actually work in practice? a 3-year experience with the Maternity Dashboard. Invited Commentary. Clin Risk 2010; 16: 176-82. 